\title{
Role of intra operative esmolol infusion in post operative pain relief after laparoscopic cholecystectomy.
}

\author{
Insha Qureshi ${ }^{1}$, Iqra Nazir ${ }^{2}$, Mubasher Ahmad $^{3}$, Velayat Nabi ${ }^{4}$, \\ ${ }_{1,2}$ (Senior Resident Anesthesiology \& Critical care, SKIMS, Srinagar, India) \\ ${ }^{3}$ (Lecturer Anesthesiology\& Critical care, GMC \& Associated Hospitals SMHS, Srinagar, India) \\ ${ }^{4}$ (Assistant Professor Anesthesiology \& Critical care, SKIMS, Srinagar, India)
}

\begin{abstract}
Postoperative pain following laparoscopic cholecystectomy is one of the main causes for lengthening the period of hospitalization. In an attempt to decrease this early postoperative complication, esmolol infusion was administered during general anaesthesia to patients undergoing laparoscopic cholecystectomy. Sixty patients ASA class I undergoing laparoscopic cholecystectomy were randomly assigned to two groups, esmolol group (Group E, $n=30$ ) and placebo group (Group P, $n=30$ ). In group E, patients received $1 \mathrm{mg} / \mathrm{kg}$ esmolol bolus dose i.v immediately before induction while as group $P$ received same volume of inj. Ringer Lactate as placebo. In group E, immediately after intubation, esmolol infusion was started at the rate of 5-10 $\mu \mathrm{g} / \mathrm{kg} / \mathrm{min}$. The rate was titrated to maintain heart rate between 65-75 beats per min. Patients in group P received $100 \mathrm{ml}$ of Ringer Lactate infusion. The incidence of PONV and pain were assessed after surgery. Incidence of postoperative analgesia requirement was significantly less in esmolol group. $50 \%$ of patients required analgesia in group E, while $83.33 \%$ required analgesia in group $P(p=0.006)$. Post operative antiemetic requirements were also significantly less in group E. It was concluded that incidence of postoperative analgesia requirements over first 24 hours after laparoscopic cholecystectomy was found to be less in esmolol group as compared to placebo group.
\end{abstract}

Key words: Esmolol, Laparoscopic cholecystectomy, Ringer lactate

\section{Introduction}

Diminished surgical trauma and associated morbidity have made laparoscopic cholecystectomy a standard technique for removal of diseased gallbladder. In spite of the high success rate of ambulatory laparoscopic cholecystectomy, the most common side effects reported with this surgery are postoperative nausea and vomiting (PONV), pain, medical complications, and urinary retention, leading to an unanticipated admission rate of approximately $5 \%{ }^{[1]}$.

One of the major challenges of ambulatory anaesthesia is the ability to provide effective post operative analgesia and hemodynamic stability, thus allowing patients to be safely discharged ${ }^{[2]}$.Postoperative pain is less after laparoscopic cholecystectomy compared to open cholecystectomy ${ }^{[3]}$ but effective analgesic treatment after laparoscopic cholecystectomy has remained a challenge. ${ }^{[4]}$ In $17-41 \%$ of patients, pain is main reason for staying overnight in hospital on the day of surgery. ${ }^{[5]}$

Adrenergic receptor antagonist have been used during surgery with intention to attenuate the stress response and decrease unwanted peri-operative hemodynamic changes ${ }^{[6]}$ Esmolol, an ultra-short-acting cardioselective $\beta$-adrenergic receptor antagonist, has been proposed as an alternative to intra operative use of opioids, and found to facilitate the fast-tracking process and speed home-readiness of patients undergoing outpatient surgery ${ }^{[7,8,9]}$

The present prospective, randomized study was designed to compare the effect of intra-operative i.v esmolol vs. placebo on incidence of post-operative pain in patients scheduled for laparoscopic cholecystectomy.

\section{Patients and Methods}

This randomized, prospective, double blind study included 60 patients of either gender, aged 18 and above, ASA 1, undergoing laparoscopic cholecystectomy under general anaesthesia. A proper approval from the local ethics committee and informed consent was taken from the patients included in the study. During preanaesthetic visit, all patients were clinically evaluated, assessed and investigated. Patients were instructed before surgery about the use of the visual analogue scale (VAS). Exclusion criteria were: ASA II, concurrent treatment with a $\beta$-blocker or a calcium channel blocker, chronic use of an opioid analgesic, history of asthma or reactive airway disease, diabetes mellitus, allergy to any drug used in study, obesity or cachexia, severe hemorrhage during surgery, conversion to open cholecystectomy or inability to comprehend pain assessment.

An anaesthetist not involved in the care of the patient prepared esmolol and placebo solution \& held the randomization cards until the end of the study. Both patient and the anaesthetist in charge were blinded to group allocation for the duration of study. The patients were shifted to the operating room, intravenous line established 
and patients were connected to Datex monitor for continuous monitoring of ECG, heart rate, non invasive blood pressure (NIBP), and oxygen saturation. All the patients received $10 \mathrm{ml} / \mathrm{kg}$ ringer lactate (RL) before induction. Patients were randomly allocated to two groups:

GROUP E--- Esmolol group $(\mathrm{n}=30)$

GROUP P ---Placebo group $(\mathrm{n}=30)$

In both the groups, anaesthesia was induced in an identical manner with Inj. propofol $2-3 \mathrm{mg} / \mathrm{kg}$ body weight and Inj. fentanyl $2 \mu \mathrm{g} / \mathrm{kg}$. Intubation was facilitated with atracurium $0.5-0.75 \mathrm{mg} / \mathrm{kg}$.

In group E, patients received $1 \mathrm{mg} / \mathrm{kg}$ esmolol (prepared to make a total volume of $5 \mathrm{ml}$ ) bolus dose i.v immediately before induction while as group P received same volume of inj. Ringer Lactate as placebo. In group E, immediately after intubation, esmolol infusion was started at the rate of $5-10 \mu \mathrm{g} / \mathrm{kg} / \mathrm{min}$. The esmolol infusion was prepared as $100 \mathrm{ml}$ solution and was administered through a chamber set. The rate was titrated to maintain heart rate between $65-75$ beats per min. Patients in group P received $100 \mathrm{ml}$ of Ringer Lactate infusion which was also prepared as a $100 \mathrm{ml}$ solution and was administered through the chamber set.

In both groups, controlled ventilation was performed. Maintenance of anaesthesia was done with isoflurane $0.4-1 \%$ in an inhaled mixture of $66 \% \mathrm{~N}_{2} 0$ and $33 \% 0_{2}$. Supplementary neuromuscular block was provided with bolus doses of atracurium. Isoflurane and $\mathrm{N}_{2} \mathrm{O}$ were discontinued when laparoscope was withdrawn and the effects of neuromuscular blocking agents were reversed at the end of the procedure. Patients in both groups received inj. ondansetron $4 \mathrm{mg}$ and inj. Diclofenac sodium $50 \mathrm{mg}$ i.m before extubation. Patients were extubated on the operating table and then transferred to the post anesthesia care unit (PACU). Whenever patients complained of pain during 24 hours post operatively, they were assessed using visual analogue scale (VAS) and patients with a VAS score of $>3$ were administered analgesics in the form of lnj Diclofenac $50 \mathrm{mg}$ i.m. Data collected was statistically evaluated and analyzed. Parametric data was expressed as mean \pm SD, thereby the inter group comparisons were made by student's t-test .The test was two sided and referred for $p$ value for its significance. P-value less than $0.05(\mathrm{p}<0.05)$ was taken to be statistically significant. The analysis was performed on SSPS version 11.3, statistical software for social sciences, Chicago, U.S.A for windows.

\section{Results}

The study recruited 60 patients with ASA status I . There were no significant group differences found in age, gender, previous history of PONV, history of smoking and motion sickness, duration of surgery and anaesthesia. ( TABLE 1)

Table 1: Comparison between demographic details \& other characteristics in two groups.

\begin{tabular}{|c|c|c|c|}
\hline CHARACTERISTICS & GROUP-E & GROUP-P & p Value \\
\hline Number of patients & 30 & 30 & $\mathrm{p}=0.240$ \\
\hline Mean age in years( \pm S.D) & $40.17 \pm 6.10$ & $41.7 \pm 3.5$ & \\
\hline Gender (F/M) & & & \\
\hline Previous PONV & $21 / 09$ & 1 & $\mathrm{p}=0.559$ \\
\hline History of smoking & 1 & 4 & $\mathrm{p}=1$ \\
\hline History of motion sickness & 1 & 0 & $\mathrm{p}=1$ \\
\hline Duration of surgery (min) & 69 & 60 & $\mathrm{p}=1$ \\
\hline Duration of anesthesia (min) & 87 & 80 & $\mathrm{p}=0.074$ \\
\hline
\end{tabular}

The mean value of mean heart rate (bpm) for group E and group P was 70.138 and 78.350 respectively. When these two values were compared, $\mathrm{p}$ value was 0.001 i.e. statistically significant. The mean heart rate did not decrease below 60 beats per minute in any patient. In addition, the MABP of group P and E was not significantly different at any point before, during or after the procedure.

Incidence of postoperative analgesia requirement was significantly less in esmolol group. 50\% of patients required analgesia in group $\mathrm{E}$, while $83.33 \%$ required analgesia in group $\mathrm{P}(p=0.006)$. (TABLE 2$)$

Table 2: Comparison of incidence of postoperative analgesia requirement (inj Diclofenac) in two groups.

\begin{tabular}{|c|c|c|c|c|}
\hline & GROUP E & GROUP P & TOTAL & p VALUE \\
\hline $\begin{array}{c}\text { Number of patients who received post } \\
\text { operative analgesia }\end{array}$ & $15(50 \%)$ & $25(83.33 \%)$ & $40(66.7 \%)$ & \\
\cline { 1 - 3 } $\begin{array}{c}\text { Number of patients who did not receive } \\
\text { post operative analgesia }\end{array}$ & $15(50 \%)$ & $5(16.77 \%)$ & $20(33.3 \%)$ & $\mathrm{p}=0.006$ \\
\hline TOTAL & $\mathbf{3 0}$ & $\mathbf{3 0}$ & $\mathbf{6 0}$ & \\
\hline
\end{tabular}




\section{Discussion}

Cholecystectomy is one of the most commonly performed abdominal operations, and the laparoscopic approach has become the standard of care. Although the minimally invasive approach allows for rapid discharge home, the recovery process can be further accelerated by modifications in other aspects of perioperative care. Despite all the benefits that have emerged with the introduction of laparoscopic cholecystectomy, post-operative pain remains an issue. Ineffectively treated post-operative pain is still one of the common surgical complications, and this medical problem may result in clinical and psychological changes that may increase morbidity and mortality as well as costs and may decrease the quality of life. ${ }^{[10]}$

The introduction of rapid and short-acting opioids, anesthetics, and neuromuscular blockers have facilitated the implementation of fast-track surgery ${ }^{[2]}$, but side effects associated with opioids, such as PONV, can still occur. Infact, pain, and PONV are the most common causes for unexpected hospital admission ${ }^{[1]}$. Anesthetic and analgesic techniques that avoid or minimize opioid use may therefore be beneficial.

Esmolol is $\beta$ adrenergic receptor antagonist that selectively affects the cardiovascular system. Its effect is rapid and it has a short half life. It is used as a supplement to reduce the hemodynamic responses to surgical stimulations. This $\beta$ adrenergic receptor antagonist has a sympathetic nerve blocking effect on PONV and pain ,the benefits of $\beta$ adrenergic antagonists in patients with cardiovascular diseases are well established ${ }^{[6]}$. Stressful interventions that cause intense activation of the sympathetic nervous system can result in cardiovascular consequences. Thus, $\beta$ adrenergic antagonists can be targeted to attenuate this unwanted response ${ }^{[11]}$

Functional magnetic resonance imaging studies in humans have also demonstrated hippocampal activation during emotional distress ${ }^{[12]}$, fear ${ }^{[13]}$, and anxiety ${ }^{[14]}$. This hippocampal activation results, in part, from the activity of stress-related factors, including norepinephrine, which enhances the excitability of hippocampal principal neurons via an interaction with hippocampal $n$-methyl-d-aspartate subtype glutamate receptors ${ }^{[15]}$. It then seems possible that the activation of hippocampal $\beta$ adrenergic receptors might play a role in nociceptive processes. If so, then blockade of these receptors should blunt the contribution of such $\beta$ adrenergic activation to the nociceptive process, thereby resulting in the attenuation of perceived pain intensity.

We used esmolol in a dose of $1 \mathrm{mg} / \mathrm{kg}$ bolus followed by an infusion at the rate of 5 to $10 \mu \mathrm{g} / \mathrm{kg} / \mathrm{min}$ in our study and compared the incidence of postoperative analgesic requirements between two groups in first 24hours. In group E only $15(50 \%)$ patients received post operative analgesics in the form of inj Diclofenac $50 \mathrm{mg} \mathrm{i} / \mathrm{m}$ as against $25(83.33 \%)$ patents in group P.

Our study is consistent with the study don e by YE Moon et al ${ }^{[16]}$ in which they concluded that intra operative esmolol infusion decreased both the requirement for sevoflurane and post operative administration of fentanyl.

Our study is showing similar results as obtained in a study done by Chai et al ${ }^{[9]}$ in which they found that morphine consumption for first three post operative days was significantly reduced in esmolol group in women undergoing abdominal hysterectomy. Vincent Collard et al ${ }^{[17]}$ found that amount of fentanyl required in post anaesthesia care unit was significantly less in esmolol group as compared to remifentanil and control group.

Our study is also consistent with the study done by Sang Jun Lee et al ${ }^{[18]}$ in which they concluded that perioperative esmolol infusion contributes to significant decrease in PONV and post operative pain and facilitates early discharge. White et al. ${ }^{[8]}$ using the gynecologic surgical model, administered $1.5 \mu \mathrm{g} / \mathrm{kg}$ of fentanyl at induction, followed by an infusion of esmolol, and found that this group required less postoperative opioids.

Secondary observations drawn from the study include mean heart rate which was compared between two groups and found to be statistically significant. It confirms that $\beta$ blockade was achieved intraoperatively using esmolol infusion at the rate of $5-10 \mu \mathrm{g} / \mathrm{kg}$. The mean value of mean heart rate (bpm) for group $\mathrm{E}$ and group $\mathrm{P}$ was 70.138 and 78.350 respectively. This is consistent with the study done by Ebert $\mathrm{J} \mathrm{P}$ et al ${ }^{[19]}$ as they concluded that esmolol blunted the heart rate response effectively in patients receiving esmolol infusion intraoperatively. The esmolol group also had the lowest incidence of post operative nausea and vomiting and received less antiemetics post operatively.

Limitations of our study include a small patient population. These beneficial results should be sought in studies with larger group of patients.

\section{Conclusion}

Our study suggests that, incidence of postoperative analgesia requirement over first 24 hours after laparoscopic cholecystectomy is less in esmolol group as compared to placebo group. 


\section{References}

[1]. Lau H, Brooks DC. Contemporary outcomes of ambulatory laparoscopic cholecystectomy in a major teaching hospital. World J Surg 2002;2 6:1117-213.

[2]. Avramov MN, White PF. Use of alfentanil and propofol for outpatient monitored anesthesia care: determining the optimaI dosing regimen. Anesth Analg 1997; 85:566-72

[3]. Hendolin HI, Pääkönen ME, Alhava EM et al. Laparoscopic or open cholecystectomy: a prospective randomized trial to compare postoperative pain, pulmonary function, and stress response. Eur J Surg. 2000 May; 166(5):394-9.

[4]. Huseyin Yilmaz, Oguzhan Arun, Seza Apiliogullari et al .Effect of laparoscopic cholecystectomy techniques on postoperative pain: a prospective randomized study J Korean Surg Soc. 2013 October; 85(4): 149-153.

[5]. O. Mentes1, A. Harlak, T. Yigiti .Effect of intraoperative magnesium sulphate infusion on pain relief after laparoscopic cholecystectomy Acta Anaesthesiol Scand 2008; 52: 1353-1359

[6]. Davidson EM, Doursout MF, Szmuk P, Chelly JE. et al Antinociceptive and cardiovascular properties of esmolol following formalin injection in rats. Can J Anaesth. $2001 \mathrm{Jan}$; 48(1):59-64

[7]. Coloma M, Chiu JW, White PF, Armbruster SC. The use of esmolol as an alternative to remifentanil during desflurane anesthesia for fast track outpatient gynecologic laparoscopic surgery. Anesth Analg 2001; 92:352-7

[8]. White PF, Wang B, Tang J, Wender RH, Naruse R, Sloninsky A. The effect of intraoperative use of esmolol and nicardipine on recovery after ambulatory surgery. Anesth Analg 2003; 97:1633-8

[9]. Chia YY, Chan MH, Ko NH, Liu K. Role of beta-blockade in anaesthesia and postoperative pain management after hysterectomy. Br J Anaesth 2004; 93: 799-805

[10]. Fisher K, Coderre TJ, Hagen NA. Targeting the N-methyl- D-aspartate receptor for chronic pain management: preclinical animal studies, recent clinical experience and future research directions. J Pain Symptom Manage 2000; 20: 358-73.

[11]. Koivusalo AM, Scheinin M, Tikkanen I, Yli-Suomu T, Ristkari S, Laakso J, Lindgren L. Effects of esmolol on hemodynamic response to CO2 pneumoperitoneum for laparoscopic surgery. Acta Anaesthesiol Scand 1998; 42:510-7

[12]. Sinha R, Lacadie C, Skudlarski P, Wexler BE. Neural circuits underlying emotional distress in humans. Ann N Y Acad Sci 2004; 1032:254-7

[13]. Surguladze SA, Brammer MJ, Young AW, Andrew C, Travis MJ, William SC, Phillips ML. A preferential increase in the extra striate response to signals of danger. Neuroimage 2003; 19:1317-28

[14]. Ploghaus A, Narain C, Beckmann CF, Clare S, Bantick S, Wise R, Matthews PM, Rawlins JN, Tracey I. Exacerbation of pain by anxiety is associated with activity in a hippocampal network. J Neurosci 2001; 15: 21:9896-903

[15]. Sarvey JM, Burgard EC, Decker G. Long-term potentiation: studies in the hippocampal slide. J Neurosci Methods 1989; 28:109-24

[16]. Moon YE, Hwang, WJ, et al. the sparing effect of low dose esmolol on sevoflurane during laparoscopic gynaecological surgery. The Journal of International Medical research 2011: vol 39; 1861-1869.

[17]. Vincent Collard et al. Intraoperative Esmolol Infusion in the Absence of Opioids Spares Postoperative Fentanyl in Patients Undergoing Ambulatory Laparoscopic Cholecystectomy. Anesthesia and Analgesia Vol. 105, No. 5, November 2007

[18]. Lee SJ, Lee SN. The effect of perioperative esmolol infusion on PONV and pain after laparoscopic appendectomy. Korean journal of Anaesthesiology 2010; vol 59(3): 179-184.

[19]. Ebert JP, Bernstein JS et al. attenuation of hemodynamic responses to rapid sequence induction and intubation in healthy patients with single bolus of esmolol. Journal of clinical Anaesthesiology 1990;vol 2(4):243-252. 